\title{
Multiplicity of Depressive Episodes: Phenomenological and Neuroendocrine Correlates
}

\author{
George N.M. Gurguis, James H. Meador-Woodruff, \\ Roger F. Haskett, and John F. Greden
}

Sixty-four patients with a Research Diagnostic Criteria (RDC) diugrosis of major depressive disorder were categorized into three groups based on their number of depressive episodes (DE): Gr I (I DE), $n=16, G r I I(2-4 D E), n=25$; and Gr III 15 or more $D E), n=23$. All patients were nonsuppressors after $1 \mathrm{mg}$ dexamethasone suppression test (DST) prior to the start of treatment. Patients were monitored during the course of their treatment lising serial Hamilton Depression scores and post-DST plasina cortisol levels. A proportionately equal number of patients in the three groups had a favorable outcome, i.e., the number of depressive episodes did not predict recovery. Despite favorable clinical outcome, patients with higher numbers of depressive episodes had significantly higher post-DST plasma cortisol levels that were above the suppressive range (greater than $5 \mu \mathrm{g} / \mathrm{dl}$ ). Patients with a higher number of depressive episoles had a significantly shorter duration of index episode and were younger at first depressive episode than patients in the other two groups. These results, however, were confounded with. polarity, with a higher number of bipolars in Gr III than in the other two groups. Results are discussed in light of pheromenological and psychoendocrine findings of earlier studies.

\section{Introduction}

The chronic, episodic, and recurrent nature of major depressive disorder represents a prominent feature in its phenomenology. Therefore, studying the effect of time course ont the phenomenolngy and neuroendocrivology of this illness could help further our understanding of the underlying pathophysiological mechanisms and prognostic aspects of depression. Particularly relevant to the neuroendocrinology of depression is the regulation of the hypothalamic-pituitary-adrenocortical (HPA) axis over the course of time. Hypothetically, the dysregulation of this system may change as the illness becomes progressively chronic. From the Clinical Studies Unit of the Michigan Depression Program, Department of Psychiatry, University of Michigan, Ann
Arbor, Ml.

Address reprint requests to Dr. George Gurguis, Biological Psychiatry Branch, NIMH, Bldg 10, Roon 3S239, 9000 Rockville Pike, Bethesda, MD 20892.

Received January 20, 1989; revised October 7, 1989.

Supported in part by NIMH Grant 1 R01-40216-01 (J.F.G.) and the Department of Psychiatry and the Theophile Raphael Fund at the University of Michigan Medical Center. Presented in part at the 41 st Annual Meeting of the Society of Biological Psychiatry, Washington, D.C., May 7-11, 1986. 
Studies that have examined this longitudinal aspect showed that nonsuppression of plasma cortisol levels in response to dexamethasone is state dependent (Caroll et al. 1976; Nuller and Ostroumova 1980; Greden et al. 1982, 1983; Gerkin et al. 1985). Reversion to a nonsuppressive status, reportedly heralded réajpe ( 7 iniswer et al. 1983), and a high degree of consistency in dexamethasone suppression test (DST) status across hospitalizations was reported (Brown and Qualls 1982; Coryell and Schlesser 1983; Grunhaus et al. 1983; Yerevanian et al. 1984). Longitudinal follow-up during index depressive episode demonstrated that nonsuppressor patients had graúual decreases in their post-DST plasma cortisol levels as they showed gradual clinical iniprovement. This normalization process was observed with a variety of trearment modalities (Greden et al. 1980; Goldberg 1980; Gold et al. 1980; Dysken et al. 1979; Papakostas et al. 1981; Holsboer et al. 1982, 1983; Yerevanian et al. 1983; Albala and Greden 1980; Albala et al. 1981; Rothschild and Schatzherg 1982; Targum 1983). Yet, despite the close temporal relationship between clinical recovery and DST normalization, investigators documented a suspopulation of patients who maintained a nonsuppressor status after clinical recovery (Griden et al. 1983; Papakostas et ai. 1981; Holsboer et al. 1982, Targum 1983); these paticnts were reportedly more prone to earlier relapse (Greden et al. 1983; Holsboer et al. 1982; Targum 1983). It is not known if such failure to suppress despite symptomatic recovery was associated with any of the chronicity parameters such ais age at first depressive episode, length of illness, number of depressive episodes, sotal $t u$ uration of being deprassed, duration of feeling well between episodes, age at index episode, and duration of iadex episode.

Sashidharan et al. (1984) found that a shorter duration of index eps soe was associated with DST nonsuppression in the absence of age, gender, polarity, and 'ieverity differences between the suppressors and nonsuppressors. Lenox et al. (1985) reportec a trend for nonsuppressors to have a significantly longer duration index epis le and length of illness and a significantly longer length of iliness in nonconverters. clinical recovery represented methodological difficulties in that study. Finally, MeadorWoodruff et al. (1987) found no significant correlationsi between a variety of chronicity parameters and pretreatment post-DST plasma cortis ol levels. These studies examined the relationship between DST status and chronicity parameters prior to treatment. We no: aware of other studies that have exanined this relationship during and after treatment in a controlled fashion. In fact, chronicity parameters are more likely to be associated with the process of neuroendocrine recovery from rather than with the onset of an episode.

In this report, we studied the effect of the number of depressive episodes on DST status during the course of an index depressive episode. We tested the hypothesis that patients with a higher number of depressive episodes continued to have higher post-LST plasma cortisol levels at the conclusion of treatment. The relationship between the number of depressive episodes and other phenomenological aspects of depressive illness was also examined.

\section{Methods}

Sixty-four patients with major depressive disorder, endogenous subtype, met inclusion criteria for this study. These patients were seen at the Clinical Studies Unit of the Michigan Depression Program. Inclusion criteria were (1) an RDC diagnosis of major depressive disorder, endogenous subtype (Spitzer et al. 1977); (2) a Hamilton score for depression equal to or higher than 15; (3) absence of physical illness or technical exclusion criteria 
that invalidate DST results; and (4) a plasma postdexamethasone level higher than 5 $\mu \mathrm{g} / \mathrm{dl}$. All patients underwent a comprehensive diagnostic evaluation by two clinicians using an unstructured interviewed. They all underwent a structured interview by a trained research staff $m$ r:mber using the Schedule for Affective Disorders and Schizophrenia (SADS) (Spitzs: and Endicott 1975). Past medical records were reviewed, whenever possibie, to confirm the longitudinal course of illness. Diagnosis was made by consensual agreement of two clinicians involved in treating the patient. A physical examination and full laboratory work-up were conducted.

Patients had a baseline $1 \mathrm{mg}$ dexamethasone suppression test (Carroll et al. 1981) at the end of the drug-free period which lasted for 10-14 days. Serial DSTs were administered during the course of treatment. Blood samples were drawn for plasma cortisol leve! determination at $8 \mathrm{AM}, 4 \mathrm{PM}$, and $11 \mathrm{PM}$. The maximum value of the three samples was used, usually the $4 \mathrm{PM}$ value. Plasma samples were frozen immediately at $-70^{\circ} \mathrm{C}$ until assayed using a modification of Nurphy's competitive protein-binding assay (Murphy 1967).

A bassline 17-item Hamilton Rating Scale for Depression (HRSD) (Hamilton 1960) was corip jieted at the end of the drug-free period. Serial Hamilton scores, obtained during the course of treatment, were rated by the patient's same primary psychiatrist, who was blind to the DST results, and coincided with the DST.

Biological therapies entailed tricyclic antidepressants (TCA), monoamine oxidase inhibitors (MAOI), electroconvulsive tharapy (ECT), lithium carbonate, or a combination of these therapies. Choice of the moxiality of treatment was based on clinical considerations of each subject. All patients received adequata biological treatment. A clinically favorable outcome was operationally defined as having a Hamilton depression score "Jwer than 10 and less than half the original score at the start $\mathrm{c}$ ? the study. This point in tim $:$ was also operationally defined as the point of conclusion of treatment.

Patients were categorized, based on the number of depressive episodes, into three groups. Group I (acute): one depres ive episode, Group II (moderately chronic): two to four depressive episodes, Group II (severely chronic): five or more depressive episodes.

Length of index depressive epivode was operationally denined as number of weeks depressed betore hospitalization plius number of weeks of hospitalizations until treatment was concluded. Age of first depressivc episode was defined as age (in years) when the patient had a depressive episode that apparently met criteria for a major depressive episode, whether or not treatment was sought. This was retrospectively determined from the history, based on the clinician's best judgment and records whenever available, but no reliability studies were conducted.

One-way analysis of variance (ANOVA) was conducted for comparison of a variety of clinical parametric variables across the three groups. $A X^{2}-t e s t$ was used for comparing the distribution of categorical yariables. Group comparison wras conducted prior to, at two time-points during the course of, and at the conclusion uf treatment. Logarithmic transformation of raw data was used in the statistical analysis when indicated.

\section{Results}

Sixty-four patients ( 21 men, 43 women) had a mean age at index episode of 56.3 ( \pm 14.3 ) years, HRSD $24.7 \pm 6.2$, age at first depressive episode $41.2( \pm 14.9)$ years, and mean length of index episute $40.1 \pm 32.4$ veeks. The mean pretreatment post-DST cortisol level was $13.1( \pm 6.3) \mu \mathrm{g} / \mathrm{dl}$. This cortisol level showed gradual decrease over the course of treatment $(7.6 \pm 5.9$ to $6.1 \pm 4.6$ to $5.8 \pm 5.6 \mu \mathrm{g} / \mathrm{dl}$ 
Table 1. Characteristics of All Subjects and Subjects with Favorable Outcome According to Their Distribution Across the Three Groups

\begin{tabular}{|c|c|c|c|c|c|}
\hline Parayiseter & $\begin{array}{c}\text { Group I } \\
\text { (1 episode) }\end{array}$ & $\begin{array}{c}\text { Group II } \\
\text { (2-4 episodes) }\end{array}$ & $\begin{array}{l}\text { Group III } \\
\text { (5 or more } \\
\text { episodes) }\end{array}$ & Statistic & $\boldsymbol{p}$ \\
\hline & \multicolumn{3}{|c|}{ All subjecis } & & \\
\hline & $n=16$ & $\mathrm{n}=\mathbf{2 5}$ & $\mathrm{n}=\mathbf{2 3}$ & & \\
\hline $\begin{array}{l}\text { Age } \\
\text { Gender } \\
\text { Polarity } \\
\text { Severity (HRSD) } \\
\text { Post-DST cortisol } \\
\text { Psychotic depression }\end{array}$ & $\begin{array}{l}54.5( \pm 15.2) \\
M=5, F=11 \\
U P=15, \mathrm{BP}=1 \\
25.9( \pm 7.3) \\
12.3( \pm 4.8) \\
N=5\end{array}$ & $\begin{array}{l}58.3( \pm 13.8) \\
M=11, F=14 \\
U P=22, B P=3 \\
25.3( \pm 5.3) \\
11.8( \pm 5.3) \\
N=7\end{array}$ & $\begin{array}{l}55.4( \pm 14.7) \\
M=5, F=18 \\
U P=8, B P=15 \\
23.4( \pm 6.3) \\
15.1( \pm 7.8) \\
N=4\end{array}$ & $\begin{array}{l}F=0.397 \\
X^{2}=2.716 \\
X^{2}=21.86 \\
F=0.914 \\
F=1.812 \\
X^{2}=3.39\end{array}$ & $\begin{array}{l}\text { N.S. } \\
\text { N.S. } \\
\text { 0.001 } \\
\text { N.S. } \\
\text { N.S. } \\
\text { N.S. }\end{array}$ \\
\hline
\end{tabular}

Subjects with favorable outcome

\begin{tabular}{llllll} 
& \multicolumn{1}{c}{$\mathrm{n}=13$} & \multicolumn{1}{c}{$\mathrm{n}=20$} & \multicolumn{1}{c}{$\mathrm{n}=19$} & & \\
\cline { 2 - 4 } Age & $\mathrm{55.5}( \pm 15.6)$ & $62.4( \pm 10.9)$ & $55.9( \pm 13.0)$ & $F=1.619$ & N.S. \\
Gender & $\mathrm{M}=4, \mathrm{~F}=9$ & $\mathrm{M}=8, \mathrm{~F}=12$ & $\mathrm{M}=13, \mathrm{~F}=16$ & $X^{2}=2.813$ & N.S. \\
Polarity & $\mathrm{UP}=12, \mathrm{BP}=1$ & $\mathrm{UP}=17, \mathrm{BP}=3$ & $\mathrm{UP}=6, \mathrm{BP}=13$ & $X^{2}=17.56$ & 0.0005 \\
Severity (HRSD) & $25.7( \pm 8.1)$ & $24.9( \pm 5.9)$ & $23.5( \pm 6.5)$ & $F=0.528$ & N.S. \\
Post-DST cortisol & $12.6( \pm 4.6)$ & $11.9( \pm 5.9)$ & $13.7( \pm 6.1)$ & $F=0.521$ & N.S. \\
\hline
\end{tabular}

Vaiues are means \pm SD.

iP = unipolar; $B P=$ bipolar.

at the conclusion of treatment). Forty-five patients had unipolar (UP) and 19 patients had bipolar (BP) depression. Of these 19 bipolar patients, 9 had a diagnosis of "probably bipolar-II." The general characteristics of patients according to their group distribution are summarized in Table 1.

Considering all patients, there were no group differences in severity and post-DST cortisol levels prine to, at two time points during the course of, or at the end of treatment. Considering only patients with favorable clinical outcome in each of the three groups, there were no group differences in HRSD scores and post-DST cortisol levels before and at two time points during the course of treatment. However, at the conclusion of treatment, there were statistically significant group differences: in post-DST plasma cortisol levels (Group I $2.8 \pm 1.8$, Group II $5.3 \pm 5.1$, Grovi; III $7.0 \pm 5.5 \mu \mathrm{g} / \mathrm{dl}$; $F=3.19$, df $=2,48, p<0.05$ ) in the abserce of differeaces in HRSD scores. Cortisol level differences were mainly between (irreps I and III $(F=6.38$, df $=29$, $p<0.01$ ). This was also true using log-tro sistomed data (7igures 1 and 2). By classifying improved patients within each orroup info suspossors versus nonsuppressors, there was a trend towards significance ( $\mathrm{J} / 13$ versus $8 / 20$ varsus $11 / 18, X^{2}=4.58$, $\mathrm{df}$ $=2, p<0.10$ ), and a significantly higher number of nonsuppressors in Group III compared to Group I $\left(X^{2}=4.41\right.$, df $\left.=1, p<0.03\right)$. Retrospective analysis of these patients with favorable clinical outcome showed to group differences in age at index episode, gender distribution, or severity; however, polarity distribution was significantly different (Table 1).

A proportionately equal number of patients in the three groups inat a favorable clinical outcome: Group I 13/16 versus Group II 15/20 versus Group III 18/22; i.e., the number of depressive episodes did not predict clinical recovery $\left(X^{2}=0.54\right.$, df $\left.=2, p=N S\right)$. The mean length of index depressive episode (weeks) was as follows: Group $150.72 \pm$ 

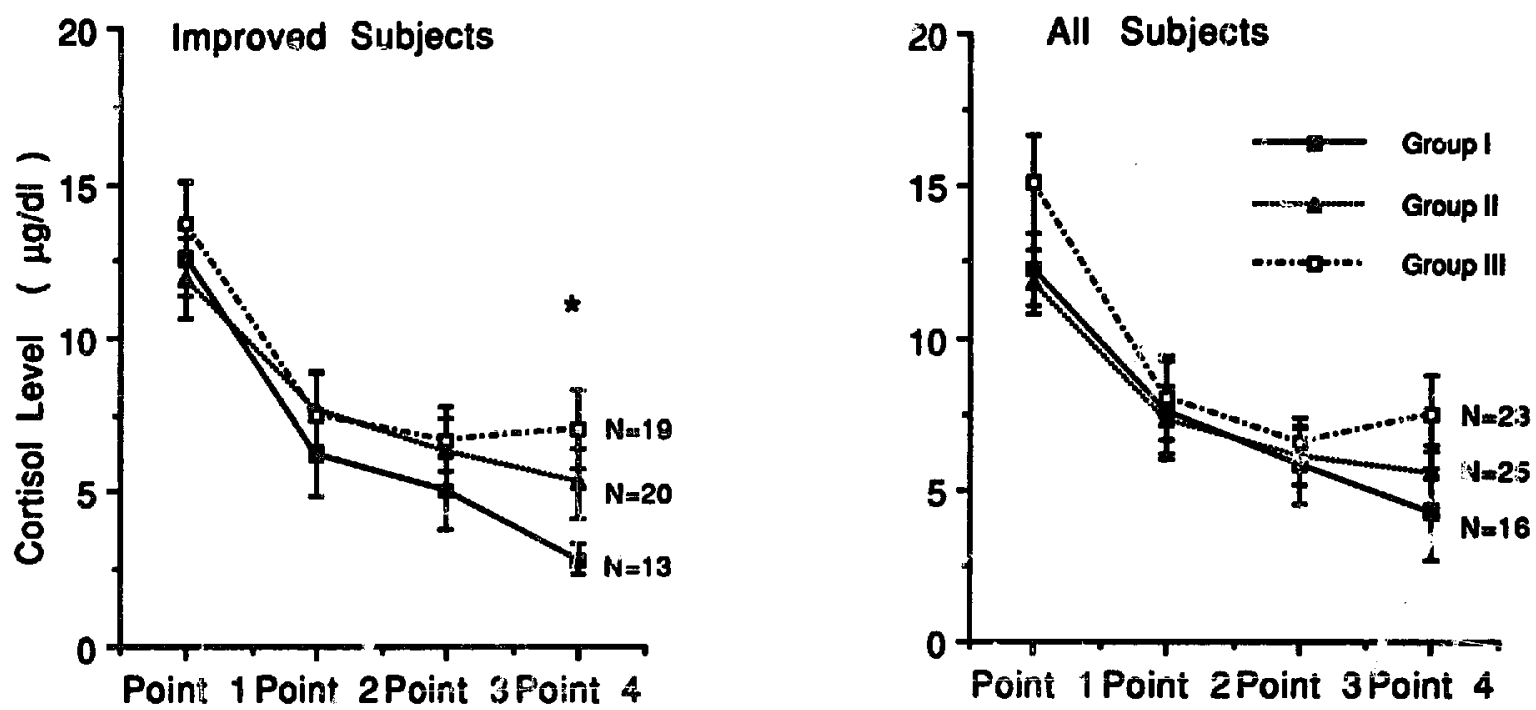

Figure 1. Cortisol levels over the course 0 . treatment of the three groups. No group differerces were observed at all time points when all subjects were considered. Improved subjects showed group differences only at the conclusion of treatment. $* p<0.05$.

38.87, Group II $46.00+32.00$, Group III $27.44 \pm 25.54(F=2.41$, df $=2,45, p$ $<0.10)$. Log-transformed data showed statistically significant group differences $(F=$ 3.3, df $=2,45, p<0.04$ ) with the severely chronic group having a shorter duration of index episode than the other two groups. The mean age (years) at first depressive episode was as follows: Group I $54.5 \pm 15.21$, Gr II $42.87 \pm 14.61$, Gr III $36.21 \pm 14.03$ (F $=7.46, \mathrm{df}=2,60, p=0.001$ ) with the severely chronic group having a younger age of onset.

Comparison between the UP and BP patients before treatment, irrespective of their
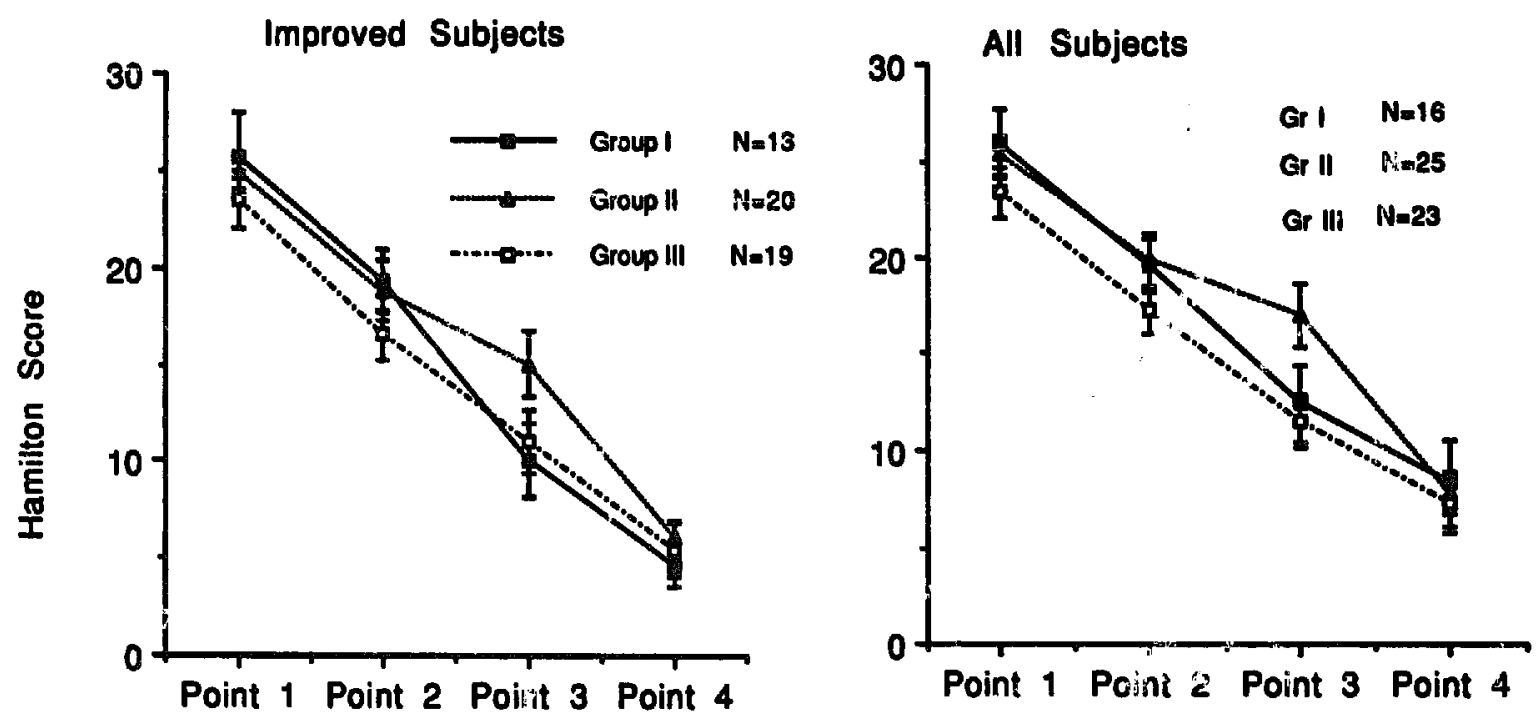

Figure 2. Hamilton scores for depression over the course of treatment of the three groups. No group differerices were observed at all time points both for all subjects and improved subjects. 
group distribution, showed that UPs had significantly higher HRSD scores $(26.0 \pm 6.3$ versus $21.76 \pm 4.7, t=2.63$, df $=62, p<0.01$ ) whereas BPs had a significantly higher number of depressive episodes $(6.31 \pm 2.7$ versus $3.0 \pm 2.4, t=4.64$, df $=$ $62, p<0.001)$, in absence of differences in clinical outcome $\left(X^{2}=1.19\right.$, $\mathrm{df}=1, p$ $=$ NS), age at first depressive episode (40.4 \pm 15.3 versus $38.2 \pm 13.4, t=0.51$, df $=45, p=\mathrm{NS})$, age at index episode $(57.5 \pm 14.4$ versus $53.6 \pm 14.1, t=0.97, \mathrm{df}$ $=62, p=N S)$, and pretreatment post-DST cortisol levels (13.2 \pm 5.4 versus $12.8 \pm$ $8.1, t=0.21, \mathrm{df}=62, p=\mathrm{NS}$ ). Finally, comparison between patients with favorabie outcome and those with unfavorable outcome before treatment, irrespective of their group distribution, showed no differences in pretreatment post-DST plasma cortisol levels (12.7 \pm 5.6 versus $14.6 \pm 8.8, t=0.916, \mathrm{df}=62, p=\mathrm{NS})$, in severity $(24.5 \pm 6.1$ versus $25.66 \pm 6.8, t=0.55$, $\mathrm{df}=62, p=\mathrm{NS})$, in gender distribution $\left(X^{2}=1.97\right.$, $\mathrm{df}=1, p=\mathrm{NS})$, or in polarity $\left(X^{2}=1.19\right.$, df $\left.=1, p=\mathrm{NS}\right)$. However, patients with favorable clinical outcome had a significantly higher mean age at index episode (58.3 \pm 13.1 versus $47.66: 16.6, t=2.4, \mathrm{df}=62, p<0.01$ ); i.e., older age predicted better outcome.

\section{Discussion}

In this study, we examined the DST normalization process and its relationship to a number of chronicity parameters in 64 patients with major depressive disorder. Phenomenological correlates of multiplicity of depressive episodes were also examined. Patients with a higher number of depressive episodes had significantly higher post-DST cortisol levels despite clinical recovery. Though there were no group differences in age, gender distribution, severity, or pretreatment post-DST plasma cortisol levels, there was a higher number of bipolar patients in Group III.

We believe this is the first study to document such a high incidence of nonsuppression among recovered patients with a high number of depressive episodes. The absence of a relationship between pretreatment post-DST cortisol levels and number of depressive episodes is consistent with earlier reports by Meader-Woodruff et al. (1987) and Lenox et al. (1985). These results are along the same lines as those of Lenox et al. regarding a significantly longer length of illness in nonconverters, though that study did not control for recovery.

Dexamethasone nonsuppression is reportedly state dependent and DST normalization is ciosely associated with clinical recovery, yet, several lines of evidence suggest that this may not be strictly so. First, DST normalization occurs prior to symptomatic recovery (Gerken et al. 1985). Second, our results, together with those of Targum (1983), Papakostas et al. (1981), Holsboer et al. (1982), and Greden et al. (1983), show that a number of patients maintain a nons ${ }_{i}$ pressive status despite clinical improvement. Third, Holsboer et al. (1983) showed that tonsuppression heralded clinical symptomatic relapse. These studies suggest the existence of a temporal lag between endocrine abnormalities and clinical symptomatolog;. It is likely that some of our patients who maintained a nonsuppreş:or status at the time of recovery converted later into suppressors; it would be of intere st to find out how long it took them to normalize. We propose that delay in the endo rine recovery could be a correlate of chronicity of depressive illness.

Pola $y$ distribution among the groups was different and could be a confounding variofe, however, several points suggest otherwise. First, 9 ot the 19 bipolar patients in this study carried a "probable bipolar Ir" diagnosis. This could have contributed to a 
seemingly uncven distribution in polarity. Second, post-DST cortisol levels of unipolars and bipolars were not different. This is consistent with a study by Zisook et al. (1985) (and four other studies cited therein) who found no difference in post-DST cortisol levels between unipolar and bipolar depressed patients using a standard $1 \mathrm{mg}$ DST. Therefore, it is unlikely that bipolar ratients contributed to higher post-DST cortisol levels. Third, given the phenomenology of bipolar disorder (Goodwin and Jamison 1984), 25\%-30\% of the patients diagnosed as unipolars, on the basis of having a first depressive episode, would later develop a bipolar disorder. Collectively, these points argue that the differences in cortisol levels were mainly due to the effect of the number of episodes.

Keller et al. (1981) underlined the theoretical notion that predictors of recovery are different from those of relapse, and suggested that the duration of index episode predicts recovery, whereas the number of depressive episodes predicts relapse. Our results are in agreement with those of Keller et al. $(1981,1982 a, b)$. In this study, a proportionately equal number of patients recovered in each group, i.e., the number of depressive episodes did not predict recovery. Earlier reports suggest that persistence of DST nonsuppression predicted a higher relapse rate (Targum 1983). In this study, nonsuppression, and consequently higher likelihood for relapse, was associated with a higher number of depressive episodes. Comparison between patients with favorable and those with poor outcome showed that older age predicted favorable outcome; otherwise, polarity, gender, severity, and post-DST cortisol levels did not predict outcome. These results are in partial agieement with those of Keller et al. (1981) regarding age, but not polarity or severity. The shorter length of index episode and younger age at onset observed in Group III could have been confounded with polarity. However, decrease in cycle length as a function of episode number was observed both in unipolar and bipolar patients (Zis and Goodwin 1979; Zis et al. 1980; Keller and Shapiro 1981).

In summary, this study shows that patients with a higher rum ar of depressive episodes maintain higher post-DST cortisol levels despite symptomati recovery and suggests the existence of a temporal lag between symptomatic and ne.srcendocrine recovery. These results require replication in prospectively designed sturises that would, hopefully, not be confounded with polarity, and would explore other aspects of the relationship between various chronicity parameters and HPA axis regulition in depressive disorders.

\section{References}

Albala AA, Greden JF (1980): Serial dexamethasone suppression test in affective disorders. Am J Psychiatry 137:383.

Albala AA, Greden JF, Tarika J, Carroll BJ (1981): Changes in serial dexamethasone suppression tests among unipolar depressives receiving electroconvulsive treatment. Biol Psychiatry 16:551560.

Brown WA, Qualls CB (1982): Pituitary-adrenal regulation over multiple depressive episodes. Psychiatry Res 7:265-269.

Carroll BJ, Feinberg M, Greden JF, et al. (1981): A specific laboratory test for the diagnosis of melancholia: Standardization, validation and clinical utility. Arch Gen Psychiatry 38:15-22.

Carroll BJ, Mendels J (1976): Neuroendocrine regulation in affective disorders. In Sachar EJ (ed), Hormones, Behavior and Psychopathology. New York: Raven Press, pp 193-223.

Coryell W, Schlesser MA (1983): Dexamethasone suppression test responise in major depression: Stability across hospitalizations. Psychiatr Res 8:179-189.

Dysken MW, Pandey GN, Chang SS, Hicks R, Davis JM (1979): Serial post-dexamethasone cortisol levels in a patient undergoing ECT. Ali J Psychiatry 136:1328-1329. 
Gerken $A_{i}$ Maier W, Holsboer F (1985): Weekly monitoring of dexamethasone suppression response in depression: Its relationship to change of body weight and psychopathology. Psychoneuroendocrinology 10:261-271.

Gold MS, Pottash ALC, פxtein I, Sweeny DR (1980): Dexamethasone suppression tect in depression and response to treatment. Lancet i:1 190.

Goldberg IK (1980): Dexamethasone suppression test as indicator of safe withdrawal of antidtpressant therapy. Lancet i:376.

Goodwin FK, Jamison KR (1984): The natural course of manic-depressive illness in neurobiology of mood disorders. In Post RM, Ballenger JC (eds), Frontiers of Clinical Neuroscience, Vol. I. Baltimore: Williams and Wilkins, pp 20-37.

Greden JF, Albaia AA, Haskett RF, et al. (1980): Notmalization of dexamethasone suppression test: A laboratory index of recovery from endogenous depression. Biol Psychiatry 15:449-458.

Greden JF, DeVigne J-P, Albala AA, et al. (1982): Serial dexamethasone suppression tests among rapidly cycling bipolar patients. Biol Psychinaty 17:455-462.

Greden JF, Gardener R, King D, Grunhaus L, Carroll BJ, Kronfol Z (1983): Dexamethasone suppression test in antidepressant treatment of melancholia: The process of normalization and test-retest reproducibility. Arch Gen Psychiatry 40:493-500.

Grunhaus L, Greden JF, Carroll BJ, Shein H (1983): The dexamethasone suppression test in repeated hospitalizations. Biol Psychiatry 18:1497-1502.

Hamilton M (1960): A rating scale for depression. J Neurol Neurosurg Psychiatry 23:56-62.

Holsboer F, Liebl R, Hofschuster E (1982): Repeated dexamethasone suppression test during depressive illness: Normalization of test result compared with clinical improvement. $J$ Affect Disord 4:93-101.

Hoisboer F, Steiger A, Maier W (1983): Four cases of reversion to abiormal dexamethasone suppression test response as indicator of clinical relapse: A prelim is report. Biol Psychiatry 18:911-916.

Keller MB, Shapiro RW (1981): Major depressive disorder: Initial results from a one-year prospective naturalistic follow-up study. J Nerv Ment Dis 169:76i- 768 .

Keller MB, Shapiro RW, Lavori PW, Wolfe N (1982a): Recovery in major depressive disorder: Analysis with the life table and regression models. Arch Cen Psych 39:905-910.

Keller MB, Shapiro RW, Lavori PW, Wolfe N (1982b): Relapse in major depressive disorder; analysis with the life table. Arch Gen Psychiatry 39:9!1-915.

Lenox RH, Peyser JM, Rothschild B, Shipley J, Weaver L (1985): Failure to normalize the dexamethasone suppression test: Association with length of illness. Biol Psychiatry 20:329_ 352.

Meador-Woodruff JH, Gurguis G, Grunhaus L, Haskett RF, Greden JF (1987): Multiple depressive episodes and p!asma post-dexamethasone cortisol level. Biol Psychiatry 22:583-592.

Murphy BEP (19;7): Some studies of protein-binding of steroids and their application to the routine micro- and ultra-micro measurement of various steroids in body fluids by competitive proteinbinding radioassay. $J$ Clin Endocrinol Metab 27:973-990.

Nuller JL, Ostroumova MN (1980): Resistance to inhibiting effect of dexamethasone in patients with endogenous depression. Acta Psychiatr Scand 61:169-177.

Papakostas Y, Fink M, Lee J, Irwin P, Johnson L (1981): Neuroendocrine measures in psychiatric patients: Course and outcome with ECT. Psychiatr Res 4:55-64.

Rothchild AJ, Schatzberg AF (1982): Fluctuating postdexamethasone cortisol leve's in a patient with melancholia. Am J Psychiatry 139:129-130.

Sashidharan SP, Freeman GP, Loudon JB, Novosel S, Beckett GJ, Gray S (1984): Dexamethasone suppression test in depressiun: Association with duration of iliness. Acta Psychiatr Scand 70:354 360.

Spitzer RL, Endicott J (1975): Schedule for Affective Disorders and Schizophrenia. New York: New York State Psychiatric Institute. 
Spitzer RL, Endicoti J, Robins E (1977): Research Diagnostic Criteria (RDC). New York: Biometrics Research Division, New York State Psychiatric Institute.

Targum S (1983): The application of serial neuroendocrine challenge studies in the management of depressive disorder. Biol Psychiatry 18:3-19.

Yerevanian BI, Olafsdottir H, Milanese E, Russutto JC, Mallon D, Baciewicz G, Sagi E (1983): Normalization of the dexamethasone suppression test at discharge from the hospital: Its prog= nostic value. I Affect Disord 5:191-197.

Yerevanian BI, Privitera MR, Milanese E, Sagi EA, Russotto JC (1984): The dexamethasone suppression test during recurrent major depressive episodes. Biol Psychiatry 19:407-412.

Zis AP, Goodwin FK (1979): Major affective disorder as a recurrent illness: A critical review. Arch Gen Psychiatry 36:835-839.

Zis AP, Grof P, Webester M, Goodwin FK (1930): Prediction of relapse in recurrent affective disorder. Psychopharmacology Bull 16(1):47-49.

Zisook S, Janowsky DS, Overall JE, Risch SC (1985): Tike dexamethasone suppression test and unipolar/bipolar distinctions. J Clin Psychictrv 46:461-465. 